\title{
Experimental study on knock mechanism with multiple spark plugs and multiple pressure sensors
}

\author{
Author, co-author (Do NOT enter this information. It will be pulled from participant tab in \\ MyTechZone) \\ Affiliation (Do NOT enter this information. It will be pulled from participant tab in MyTechZone)
}

\begin{abstract}
Engine knock is an abnormal phenomenon, which places barriers for modern Spark-Ignition (SI) engines to achieve higher thermal efficiency and better performance. In order to trigger more controllable knock events for study while keeping the knock intensity at restricted range, various spark strategies (e.g. spark timing, spark number, spark location) are applied to investigate on their influences on knock combustion characteristics and pressure oscillations. The experiment is implemented on a modified single cylinder Compression-Ignition (CI) engine operated at SI mode with port fuel injection (PFI). A specialized liner with 4 side spark plugs and 4 pressure sensors is used to generate various flame propagation processes, which leads to different auto-ignition onsets and knock development. Based on multiple channels of pressure signals, a bandpass filter is applied to obtain the pressure oscillations with respect to different spark strategies. Finally, the relationships among in-cylinder pressure, knock intensity, pressure fluctuation, heat release and measurement location, are analyzed to get better understanding on knock mechanism, influence factors and measurement methods. The main results show that: Igniting two spark plugs simultaneously brings higher knock amplitude than single spark ignition, however, adding more spark sites could effectively suppress the knock strength and rate of recurrence. A function $(\mathrm{Y}=-0.25 \mathrm{X}+2.82)$ is fitted to illustrate the relations between the crank angle of 1st peak of knock oscillation and MAPO. Besides, the correlations among MAPO and other influential factors are evaluated. Moreover, the pressure sensors installed around the liner give different pressure fluctuations, which indicate the directionality of pressure wave transmission in cylinder during knock process.
\end{abstract}

\section{Introduction}

Nowadays, the spark ignition (SI) engine has been widely applied because it is superior at low emissions, e.g. unburned hydrocarbon (UHC) carbon monoxide (CO), nitric oxide (NOx) and particulates. Besides, some modern technologies are implemented on the SI engine, such as downsizing, down-speeding and high compression ratio, which endow the SI engine with great potential for further improving the engine efficiency. However, the applications of these technologies have been restricted by engine knock [1].

Engine knock refers to the noise associated with in-cylinder end gas auto-ignition ahead of the propagating flame front arrival [2,3], which has long been an inherent problem that affect the engine thermal efficiency and service life. Moreover, the engine knock increases the engine vibration and noise, and heavy knock may directly lead to the engine failure by physical damage and overheating $[4,5]$. A large amount of knock studies have been carried out on knock occurrence prediction [6-10], knock suppression [1113], and knock generation mechanism study [14-16]. However, because of the random nature led by engine cycle-to-cycle variations and some other unobservable effects such as the unburned end-gas mass or hot spot temperature gradient [17-19], the knock phenomenon is randomly observed from cycle to cycle. Thereby, it is time and energy consuming to obtain the statistical data of knock behavior.

This work applies a multiple spark ignition system to explore the possibility of introducing knock at stoichiometric conditions, as the in-cylinder pressure and temperature are higher with igniting multiple plugs simultaneously. Besides, in order to produce different autoignition sites as well as the following knock evolution processes, a series of spark strategies are used to control flame propagation headways. The multiple spark ignition is firstly introduced to reduce the cold start problems $[20,21]$ and to extend the lean combustion limit and EGR tolerance while keeping low cycle-to-cycle variability [22-27], currently the multiple spark ignition is mainly used in highspeed internal combustion engines such as racing cars, motorcycles and outboard motors in attempts to eliminate missing and partial burn combustions, minimize the combustion variability, reduce the fuel consumption as well as UHC and NOx emissions [26, 28, 29]. Besides, Kartha et al. [30] reported that multiple spark plug configuration yielded the least NOx emissions compared against single spark combustion with equivalent ignition energy, and specially, side spark ignition was ideal for low UHC and CO emissions. More important, Michal Pasternak et al. [31] applied 0D/3D Simulations to estimate the spark plug number effects on knock occurrence, and the results indicated that the multiple spark ignition is more accessible to engine knock compared with single spark ignition, and ignition timing retardation was needed for multiple spark ignition to achieve the similar knock limit. Therefore, it is time and energy saving to implement knock study through multiple spark ignition, as it is more susceptible to knock events. More important, the different knock mechanisms (e.g. auto-ignition sites, pressure wave disseminations, knock intensities etc.) along with various spark strategies, are still unclear. Therefore, this study aims to analyze the knock properties and probe into the developing mechanisms with multiple spark ignition scheme.

During engine knock cycles, the heat release rate is fairly high, and the resulted high local pressure leads to pressure wave spreading across the combustion chamber. Consequently, the pressure distribution in cylinder is non-uniform [32]. Besides, the interactions between pressure waves and flame front always lead to in-cylinder 
pressure oscillations [33]. For knock research, it is important to figure out how pressure wave is formed, how it initiates knocking combustion and what kind of knock it causes. M. Pöschl [34] and Wei [35] demonstrated the in-cylinder pressure wave propagation, interaction and reflection phenomenon during knock cycles, which could be reflected by the differences of pressure data measured at different locations in combustion chamber. Hiroshi Terashima et al. [36] investigate the pressure wave effects on the end-gas autoignition and indicated that wall reflection of pressure wave promoted the auto-ignition progress and knock intensity. Wei et al. [37] showed that the pressure wave propagation and reflection may trigger the deflagration to detonation transition, which conversely enhance the high pressure vacillation. Noteworthy, the former investigations mainly analyze the spreading pressure waves by simulation, and few studies experimentally research the whole knock developing processes with different operating conditions on SI engine. In this work, a single-cylinder CI research engine is converted to run at knock conditions under SI mode. Together with a customized metal flat piston, a pancake cylinder space is created for the future laser optical research on knock. In addition, apart from the top pressure sensor mounted on the cylinder head, another four side transducers are installed circumferentially around the liner, hence the in-cylinder pressure fluctuation processes during knock cycles could be detected and analyzed with multiple pressure signals. With the current set-up, the following questions are proposed:

Towards the different spark strategies, how much will the knocking combustion characteristics be affected during this process? Will the maximum knock be found where we expect the end gas to be, just between the spark plugs, or close to the spark plugs? For different spark strategies, will we see a difference depending on where we measure the pressure? In terms of pressure oscillations, at what conditions will we see high MAPO (maximum amplitude of pressure oscillation)? Does the oscillation peak amplitude rely on the heat fraction at knock onset?

\section{Experiment setup}

\section{Engine system}

The test engine is modified based on a single-cylinder CI engine (AVL-5402), and the test engine system is controlled by the AVL PUMA Open Automation System. The engine setup diagram is shown in Figure 1, and the corresponding specifications are listed in Table 1. The inlet manifold is added with port fuel injection (PFI) part, together with a Bosch port injector (62354). A metal liner is specially designed to be circumferentially mounted with 4 spark plugs and 4 pressure sensors. Besides, the spark gap of spark plug is adjusted to $0.3 \mathrm{~mm}$ to get stable combustion with side ignition in cylinder. As are shown in Figure 2, these side installed plugs and transducers are labeled from 1 to 4 respectively, so as to identify individual spark and measurement locations. The outer diameter and inner diameter of the metal liner are $135 \mathrm{~mm}$ and $85 \mathrm{~mm}$ respectively, the liner height is $29 \mathrm{~mm}$, and the flat piston diameter is $83.5 \mathrm{~mm}$.

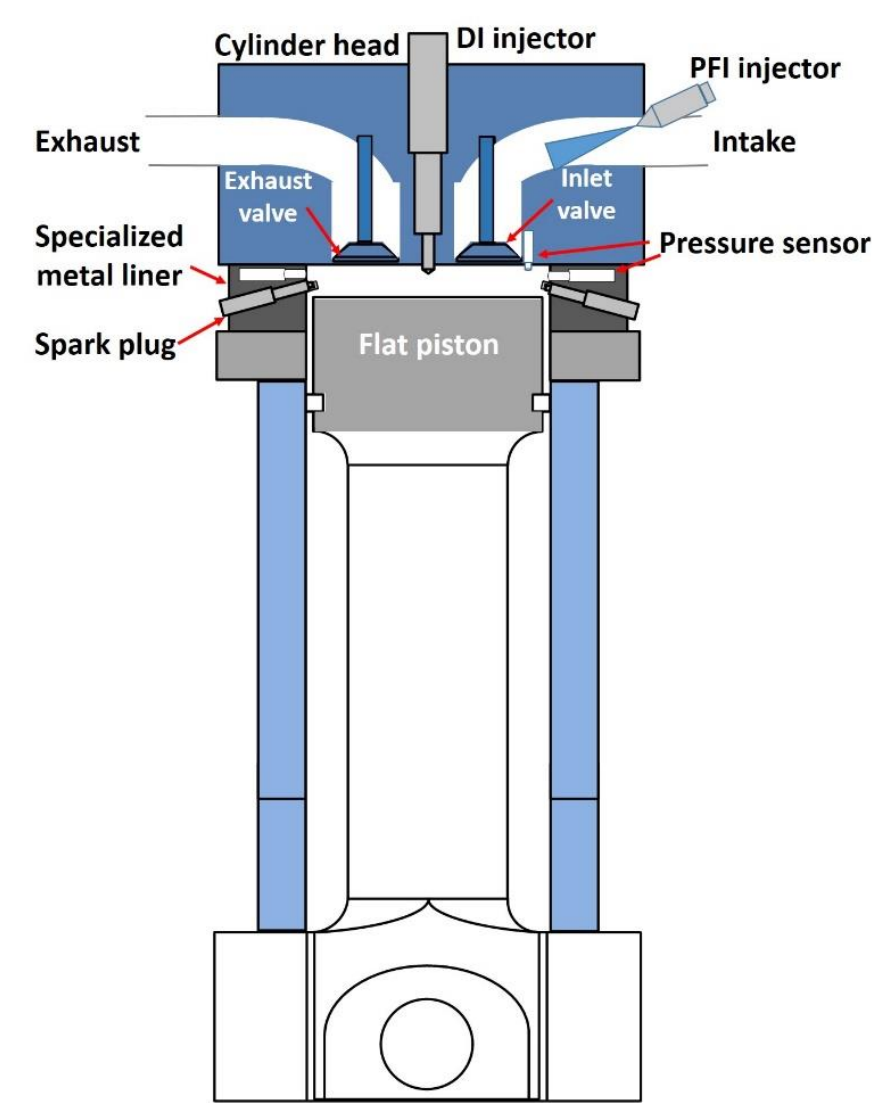

Fig. 1. Engine setup

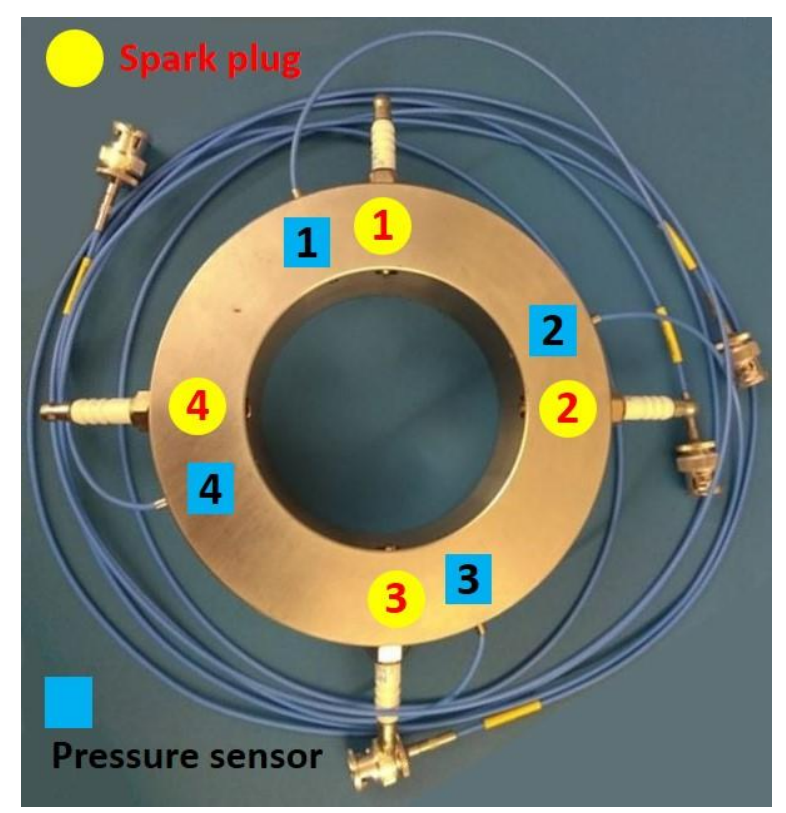

Fig. 2. Specialized liner with 4 spark plugs and 4 pressure sensors 


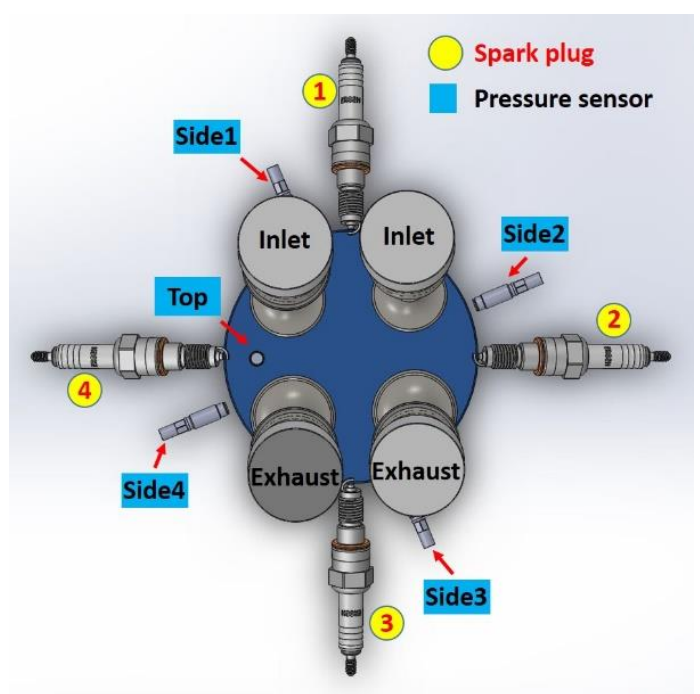

Fig. 3. Arrangements of pressure sensors and spark plugs

Figure 3 shows the overlooked arrangements of probes and spark plugs, among them the four side sensors are evenly embedded in the liner, and monitor the pressure fluctuations from different sides through drilled holes. Besides, another pressure sensor is installed near the exhaust valve of cylinder head, with an offset of $35 \mathrm{~mm}$ from the center. In addition, the side spark plugs are mounted with $15^{\circ}$ offsets near the pressure sensors, and the tips are placed horizontally above the flat piston, in order to generate flame kernels inside chamber, while avoiding the collision between piston and spark plugs. The specifications of transducers and spark plugs are listed in Table 2 and Table 3 respectively.

Table 1. The engine specifications

\begin{tabular}{|l|l|}
\hline Description & Specification \\
\hline Type & Single-cylinder research engine \\
\hline Stroke & $90 \mathrm{~mm}$ \\
\hline Bore & $85 \mathrm{~mm}$ \\
\hline Swept volume & $511 \mathrm{cc}$ \\
\hline Compression ratio & 9 \\
\hline Piston geometry & Flat \\
\hline Valve type & DOHC \\
\hline Number of valves & Intake $(2)$ Exhaust $(2)$ \\
\hline \multirow{2}{*}{ Intake valve } & Open $30^{\circ} \mathrm{CA}$ bTDC \\
\cline { 2 - 2 } & Close $45^{\circ} \mathrm{CA}$ aBDC \\
\hline \multirow{2}{*}{ Exhaust valve } & Open $50^{\circ} \mathrm{bBDC}$ \\
\cline { 2 - 2 } & Close $25^{\circ}$ aTDC \\
\hline
\end{tabular}

Table 2. Specifications of pressure sensors

\begin{tabular}{|c|c|c|}
\hline Description & \multicolumn{2}{|c|}{ Specification } \\
\hline Type & GU22CK, AVL & GH15DK, AVL \\
\hline $\begin{array}{c}\text { Measuring } \\
\text { range }\end{array}$ & $0-350 \mathrm{bar}$ & $0-300 \mathrm{bar}$ \\
\hline Overload & $400 \mathrm{bar}$ & $350 \mathrm{bar}$ \\
\hline Sensitivity & $34 \mathrm{PC} / \mathrm{bar}$ & $19 \mathrm{PC} / \mathrm{bar}$ \\
\hline Linearity & $\leq \pm 0.3 \% \mathrm{FSO}$ & $\leq \pm 0.3 \% \mathrm{FSO}$ \\
\hline $\begin{array}{c}\text { Natural } \\
\text { frequency }\end{array}$ & $96 \mathrm{kHz}$ & $170 \mathrm{kHz}$ \\
\hline $\begin{array}{c}\text { Operating } \\
\text { temperature } \\
\text { range }\end{array}$ & $-40-400{ }^{\circ} \mathrm{C}$ & $-40-400{ }^{\circ} \mathrm{C}$ \\
\hline \multirow{2}{\text{Thermal}}{$\begin{array}{c}\text { sensitivity } \\
\text { change }\end{array}$} & $\begin{array}{c}\leq \pm \%, 20-400{ }^{\circ} \mathrm{C}, \\
0-300 \mathrm{bar}\end{array}$ & $\leq 2 \%, 20-400{ }^{\circ} \mathrm{C}$, \\
\cline { 2 - 3 } & $0-300 \mathrm{bar}$ & $\leq \pm 00 \mathrm{bar}$ \\
\hline
\end{tabular}

\begin{tabular}{|c|c|c|}
\hline $\begin{array}{c}\text { Thermal shock } \\
\text { error } \Delta \mathrm{p} \text { (short- } \\
\text { term drift) }\end{array}$ & $\leq \pm 0.3$ bar & $\leq \pm 0.4$ bar \\
\hline
\end{tabular}

Table 3. Specification of spark plug

\begin{tabular}{|l|l|}
\hline Description & Specification \\
\hline Type & ER8EH, NGK \\
\hline Size & $8.0 \mathrm{~mm} \times 19.0 \mathrm{~mm} \times$ Hex 13.0mm \\
\hline Heat Range & 8 \\
\hline Spark Gap & $0.3 \mathrm{~mm}$ \\
\hline Interference suppression & $5 \mathrm{kOhm}$ \\
\hline
\end{tabular}

\section{Operating conditions}

During engine operation, the inlet temperature and pressure are adjusted by an air heater and a pressure regulator respectively, and their values are kept at $25^{\circ} \mathrm{C}$ and 1 bar. Both of the coolant and oil temperature are set at $90^{\circ} \mathrm{C}$ through the AVL PUMA system. This work is performed with normal aspiration condition, and the incylinder pressure is measured by the top pressure transducer amounted on the cylinder head, simultaneously with another 4 pressure sensors around the liner, and the measurement data is recorded in increments of 0.2 CAD. In addition, a wideband UEGO lambda sensor is used together with the electronic control unit (ECU) to keep the air/fuel ratio at stoichiometric state. Besides, the injection pressure is set at 6 bar, the injection timing is fixed at $-330 \mathrm{CAD}$ aTDC and the injection duration is maintained at $9500 \mu \mathrm{s}$.

In the experiment, the engine speed is kept at $1200 \mathrm{rpm}$, and the conditions are monitored for 200 continuous cycles to ensure steadystate operation before measurement every time. After that, another 200 continuous firing cycles are recorded with the AVL data acquisition system. In addition, the metal liner and piston are cleaned regularly to avoid pre-ignition and super-knock induced by deposit. The different engine operation parameters are listed in Table 4.

\section{Fuel system}

The fuel injection is governed by the IAV FI2RE commander software, including the injection timing and injection duration, and the injector current signals are monitored by the IndiCom module (IndiCom 2.4, AVL). Besides, the fuel is injected at the same timing ( $\mathrm{SOI}=-330 \mathrm{CAD}$ aTDC), and fuel temperature is kept stable through AVL Fuel Temperature Control (AVL-753C, AVL), and the fuel flow rate is monitored by an AVL Fuel Mass Flow Meter (AVL735S, AVL). The Haltermann CARB LEV III E10 gasoline is used in this study, which is comprised of $22.5 \%$ aromatics and $10 \%$ ethanol by volume. The detailed test fuel properties are listed in Table 5 .

Table 4. Operating parameters

\begin{tabular}{|l|l|}
\hline Engine speed & $1200 \mathrm{rpm}$ \\
\hline Intake pressure & 1 bar \\
\hline Intake temperature & $25^{\circ} \mathrm{C}$ \\
\hline Coolant temperature & $90^{\circ} \mathrm{C}$ \\
\hline Oil temperature & $90^{\circ} \mathrm{C}$ \\
\hline Injection pressure & 6 bar \\
\hline
\end{tabular}




\begin{tabular}{|l|l|}
\hline Injection timing & $-330 \mathrm{CAD}$ aTDC \\
\hline Injection duration & $9500 \mu \mathrm{s}$ \\
\hline Relative air/fuel ratio $(\lambda)$ & 1 \\
\hline
\end{tabular}

Table 5. Properties of the Haltermann CARB LEV III E10 Certification

Gasoline used in this study.

\begin{tabular}{|l|l|}
\hline Research octane number (RON) & 91.0 \\
\hline Motor octane number (MON) & 83.4 \\
\hline Specific Gravity (SG) & 0.7483 \\
\hline Lower heating value (MJ/kg) & 41.9 \\
\hline Energy density (MJ/L) & 31.4 \\
\hline Aromatics (\% v/v) & 22.5 \\
\hline Olefins (\% v/v) & 5.7 \\
\hline Ethanol (\% v/v) & 10.0 \\
\hline H/C ratio & 1.982 \\
\hline O/C ratio & 0.0336 \\
\hline
\end{tabular}

\section{Research methods}

\section{Different sparking strategies}

As is shown in Fig. 3, four spark plugs are evenly mounted around the metal liner, through which various flame propagation processes could be triggered by using different spark ignition strategies under SI mode. Noteworthy, the plug 1 is installed at the inlet valve side, while the plug 3 is near the exhaust valves. In addition, another four pressure transducers are installed close to the spark plugs, with $15^{\circ}$ space for each pair. In this case, the pressure sensors could detect the pressure vibrations from different directions around the liner, and help to predict the potential auto-ignition sites based on multiple channels of pressure signal.

Figure 4 shows the different spark strategies implemented in this study, through which 1-4 spark plugs could be triggered at different locations and different spark timings, to generate various controllable end-gas zone. Together with the pressure probes at different positions, we could investigate the knock happened at different locations in cylinder. Previous studies $[15,33,38]$ indicate that knock is more likely to initiate near exhaust valves rather than inlet valves, since they have higher temperature and more accessible to hot deposit. Therefore, for single spark ignition we tend to activate plug 1 , which leaves the end-gas zone near exhaust valve and improved the knock propensity for investigation.

As is illustrated in Fig. 9, except for single spark ignition, the spark timing is started from TDC and swept with 2-3 CAD intervals, which provoke transitions from normal combustion to conventional knock at naturally aspirated condition [38-40]. In addition, to get rid of potential risks caused by knock, the knock limited timings for different spark strategies are adjusted to keep the mean knock intensity below 6 bar, which is determined by the AVL Indicom operating system. Moreover, for the single spark ignition, the cycleto-cycle variability $(\mathrm{CCV})$ is high when activating the plug at late timings (-10 CAD aTDC to TDC), as the combustion is mild due to long combustion duration with side spark ignition.
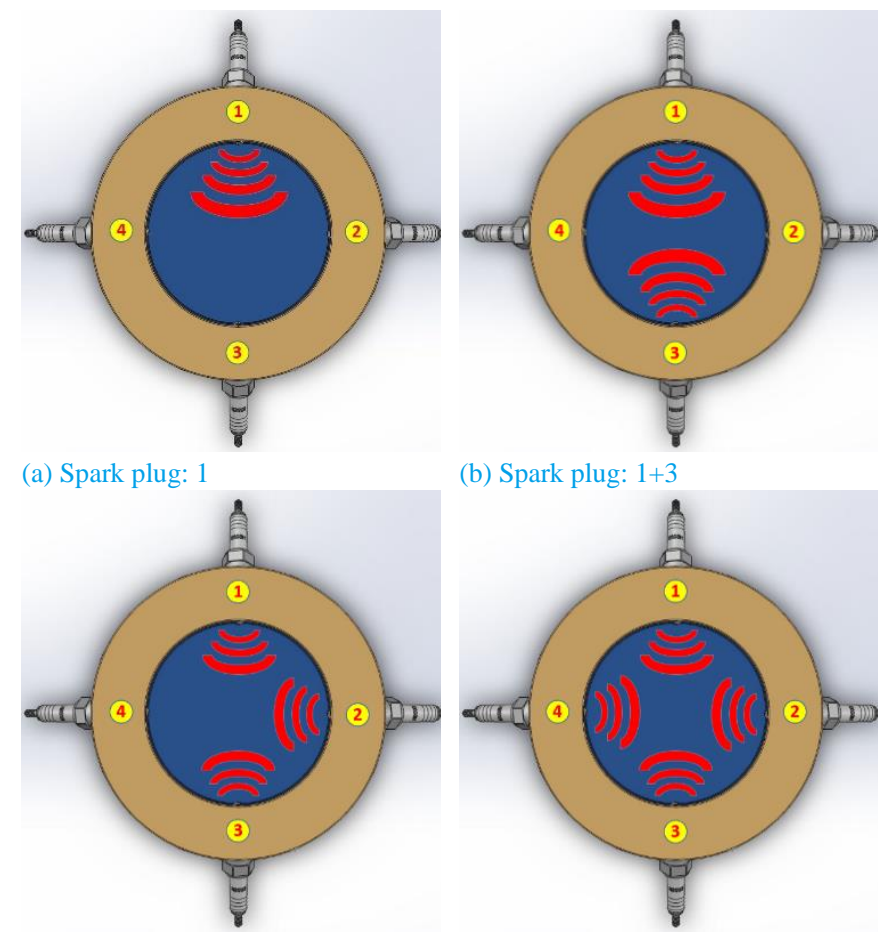

(b) Spark plug: $1+3$

(c) Spark plug: $1+2+3$

Fig. 4. different spark ignition strategies

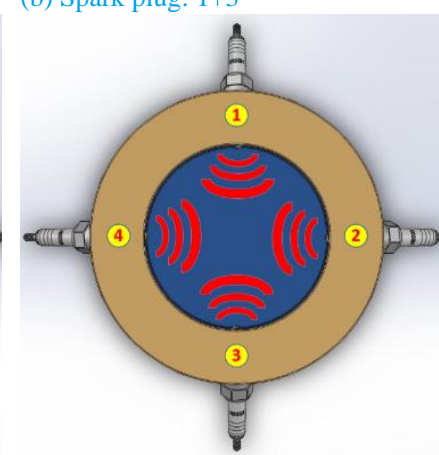

(d) Spark plug: $1+2+3+4$

\section{Band-pass filtering and pressure oscillation quantification}

As the pressure oscillation during knocking cycles consists of interfere resulted from combustion and background noises, the raw pressure signal should be band-pass filtered and attenuate frequencies outside of the given range.

A band pass filter with $6-10 \mathrm{kHz}$ frequency range [41] is applied to analyze the nature of in-cylinder pressure fluctuations, based on the pressure signals obtained by the five pressure transducers. The sampled pressure trace and filtered pressure signal of normal combustion and knock cycles are shown in Fig. 5 and Fig. 6 respectively. Here the sampled pressure traces are collected from the specific cycle with maximum MAPO at each condition.

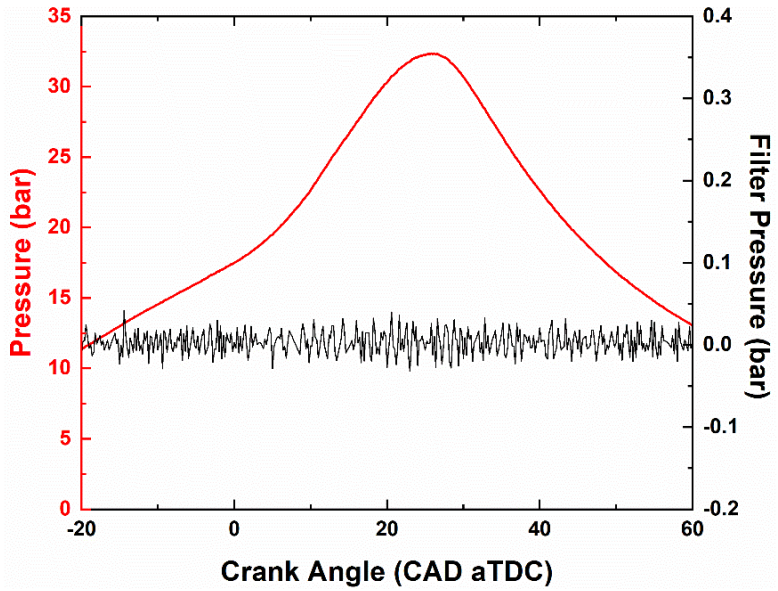

Fig. 5. The pressure trace and filtered pressure of sparking plug 1 and ST = -15 CAD aTDC 


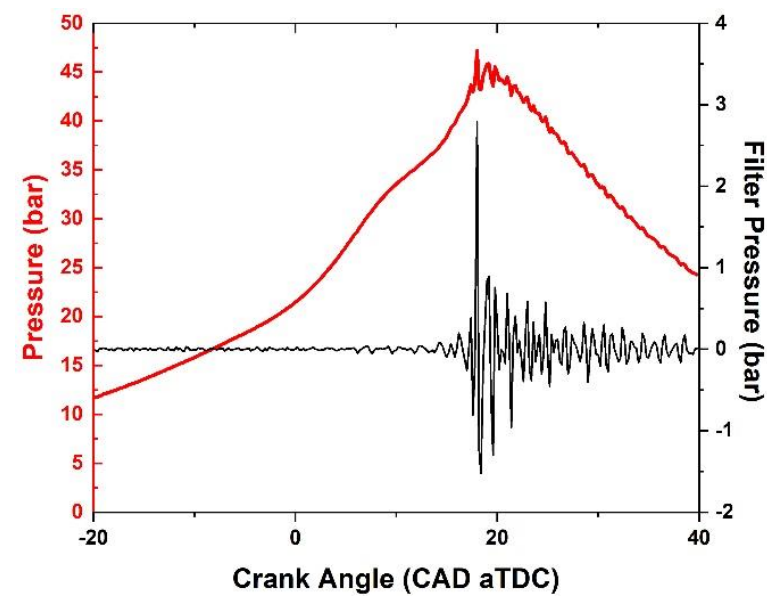

Fig. 6. The pressure trace and filtered pressure of sparking plug 1 and $\mathrm{ST}=$ -25 CAD aTDC

Moreover, the filtered pressure data is evaluated [32] to calculate the knock intensity (KI) according to peak-to-peak criteria [42, 43]:

$$
K I=\int\left|P_{B P F}\right| d \theta
$$

Where $P_{B P F}$ refers to the band-pass filtered pressure.

In this study, the cycles with KI smaller than 0.2 bar are considered as "normal cycles" [39], while the KI is kept below 6 bar to avoid potential risks. According to the knocking cycle shown in Fig. 6, the pressure trace vibration indicates the initial auto-ignition occurrence, which continues for several crank angles and followed by an abrupt pressure increase. In order to analyze the positions, heights as well as widths of the local maxima of the input signal, the signal analyzer toolbox in Matlab is applied here. Firstly, all the negative peaks are converted into positive ones, according to their absolute values. After that, we set a threshold at 0.05 bar, to differentiate the pressure oscillations under knock condition (Fig. 6) and normal combustion (Fig. 5). Next, we turn all the negative peaks to positive ones, to evaluate the variations of oscillation strength with time. As is shown in Fig. 7, all the pressure oscillation peaks whose absolute value higher than the preset threshold (red line, 0.05) are located successively, and the characteristics of signal fluctuations are valued and analyzed.

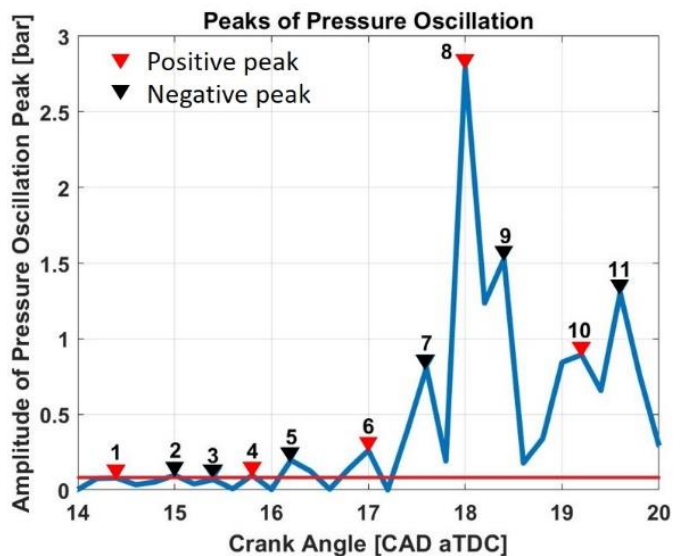

Fig. 7. Peaks of filtered pressure signal of sparking plug 1 and $\mathrm{ST}=-25$ CAD aTDC
In this study, the knock onset is determined according to the crank angle at maximum amplitude of band pass filtered (bpf) pressure signal $[44,45]$. In addition, the "pre-peaks" are defined as the pressure oscillation peaks before the peak with maximum amplitude, while the "post-peaks" refer to those peaks after the peak with maximum amplitude.

\section{Correlation coefficient}

The Spearman correlation coefficient is used to evaluate the knock related factors, which is a nonparametric measure to justify the relevance degree between two variables. The expression of the Spearman correlation coefficient is expressed as [46] :

$r_{S}=\frac{\sum_{i}\left(x_{i}-\bar{x}\right)\left(y_{i}-\bar{y}\right)}{\sqrt{\sum_{i}\left(x_{i}-\bar{x}\right)^{2} \sum_{i}\left(y_{i}-\bar{y}\right)^{2}}}$

Where $x_{i}, y_{i}$ are ranks of variables, and $\bar{x}$ and $\bar{y}$ are the corresponding mean values.

\section{Results and discussion}

\section{Pressure trace and HRR (heat release rate) analysis}

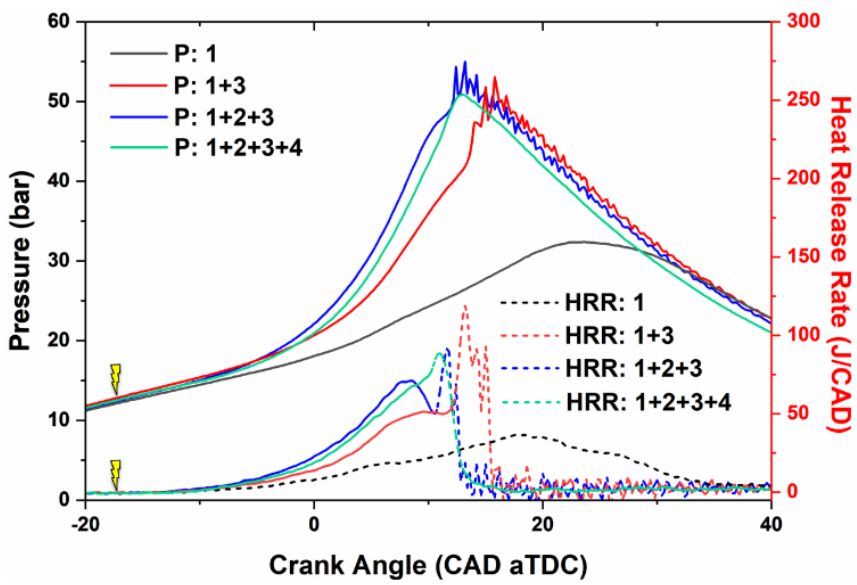

Fig. 8. The pressure traces and heat release rates with respect to different spark strategies $(\mathrm{ST}=-17 \mathrm{CAD}$ aTDC)

Fig. 8 shows the pressure traces and heat release rates with respect to different spark strategies, while keeping the same spark timing (-17 CAD aTDC). The pressure rise of sparking plug 1 is most moderate, while the pressure traces of sparking plug $1+3$ and plug $1+2+3$ increase fiercely, the fluctuations are more intense along with higher peak pressures. However, the maximum in-cylinder pressure decreases when sparking all four spark plugs, and the pressure trace becomes smoother. Overall, the combustion phasing is more advanced when introducing more spark plugs except igniting 4 spark plugs. Compared with other HRRs, the HRR of triggering plug 1 is milder along with a longer duration. The HRRs of sparking plug $1+3$ and plug $1+2+3$ arise rapidly after knock occurrence, and large amounts of heat are released during knocking process. In comparing with triggering plug $1+3$, the combustion phasing is further forward and the knock onset is more advanced when triggering plug $1+2+3$. However, the combustion becomes smooth and the combustion phasing is advanced apparently when igniting plugs $1+2+3+4$ simultaneously, which denotes that excessive number of ignition sites 
could accelerate the combustion process and suppress the knock occurrence.

In terms of sparking $1+2+3+4$, the combustion is gentler when comparing other spark strategies, and the combustion phasing is foremost, which denotes that excessive number of ignition sites could accelerate the combustion process and suppress the knock occurrence.

\section{Combustion phasing}

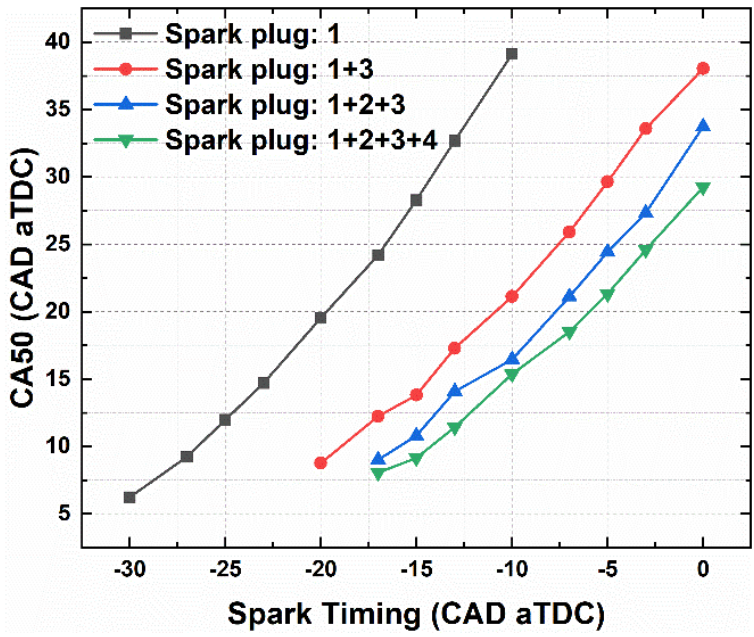

Fig. 9. CA50 regarding various spark timings and spark strategies

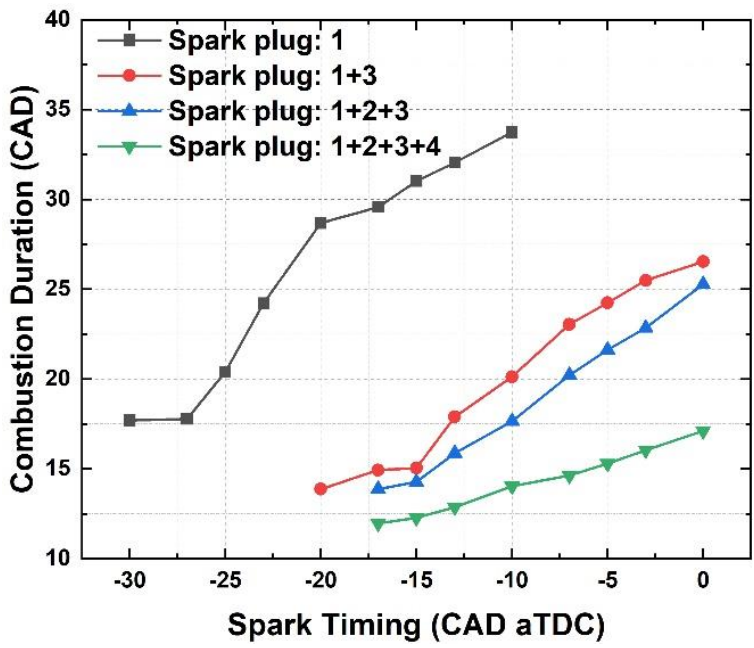

Fig. 10. Combustion duration regarding various spark timings and spark strategies

Figure 9 displays the CA50 with respect to different spark timing (ST) and different spark strategies. With advancing the ST, the CA50 is brought forward continuously for different spark strategies. Besides, the ST can be retarded more than $10 \mathrm{CAD}$ to achieve the similar CA50 when using multiple spark ignitions. To be specific, the ST is earlier than -10 CAD aTDC to keep stable combustion when triggering plug 1 singularly, and it can be advanced to -30 CAD aTDC within knock limit. In comparison, the ST can be delayed to TDC with stable combustion for multiple spark ignition, and it need to be later than -20 CAD aTDC with acceptable knock intensity. Moreover, there are distinguish gaps among various spark strategies with respect to the same ST, the CA50 can be advanced by as much as $23 \mathrm{CAD}$ with the increased ignition sites. This is due to the fact that more spark ignition leads to larger flame area and higher flame propagation speed.

Figure 10 shows the combustion duration (CD, defined as CA90CA10) variations with advancing the spark timing, regarding different sparking methods. In comparison, more spark plugs lead to shorter combustion durations, which is consistent with the HRR traces shown in Fig.8. Besides, the single spark ignition (spark plug: 1) witnesses obviously longer durations (e.g., $34 \mathrm{CAD}$ with ST at -10 CAD aTDC) than other spark strategies, which is attributed by the longer flame spreading distance from single side plug and lower flame speed, compared with other cases. Moreover, with more spark plugs, the shorter CD variations are observed with earlier ST, which is because activating more plugs leads to higher in-cylinder temperature and induces higher flame speed.

\section{Knock intensity (KI) distribution and peak value variation}

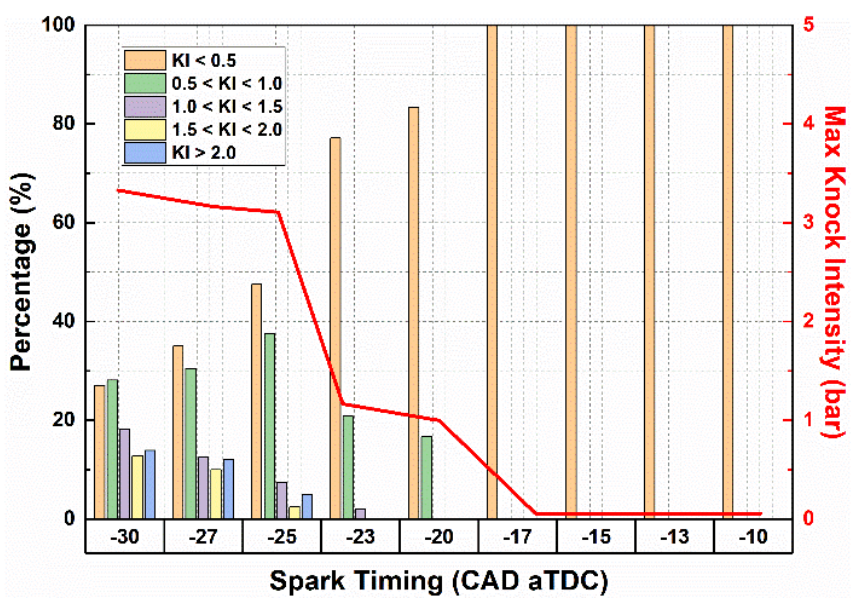

a) Spark plug: 1

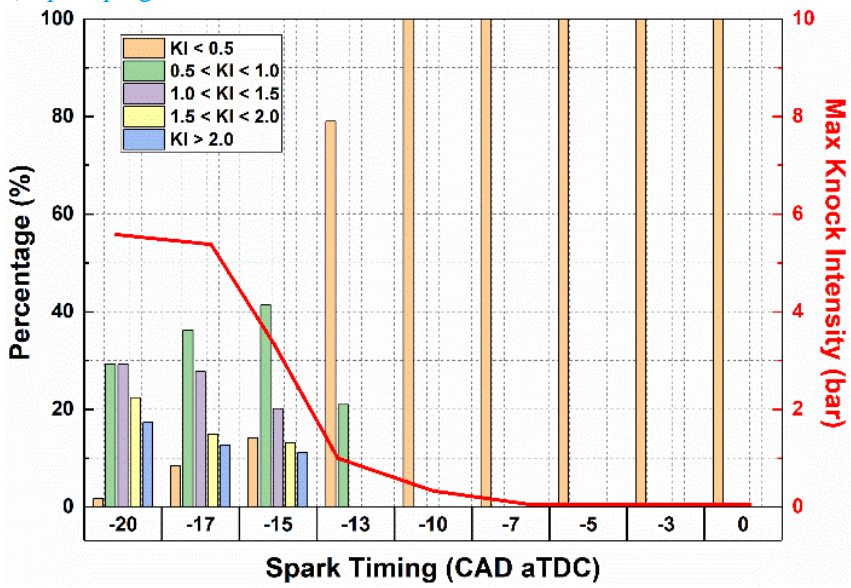

b) Spark plug: $1+3$ 


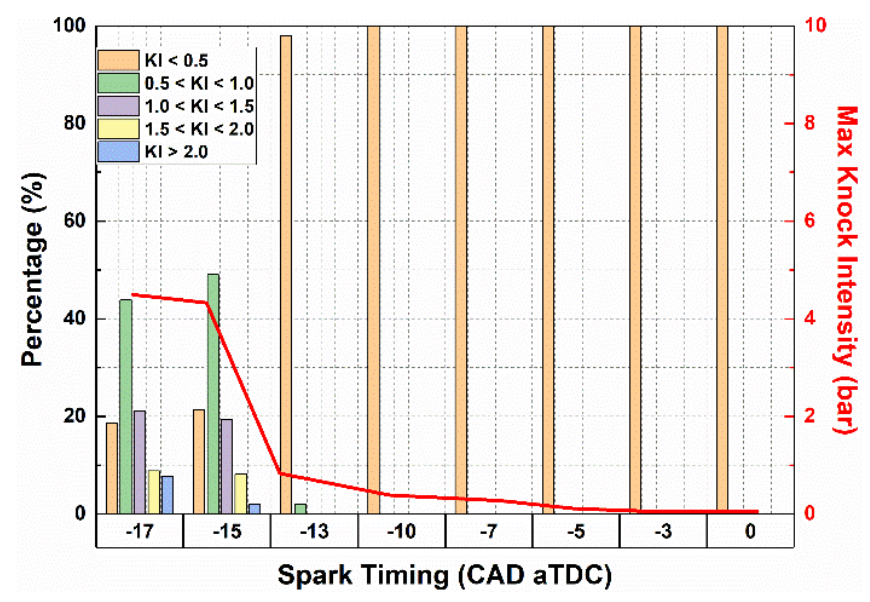

c) Spark plug: $1+2+3$

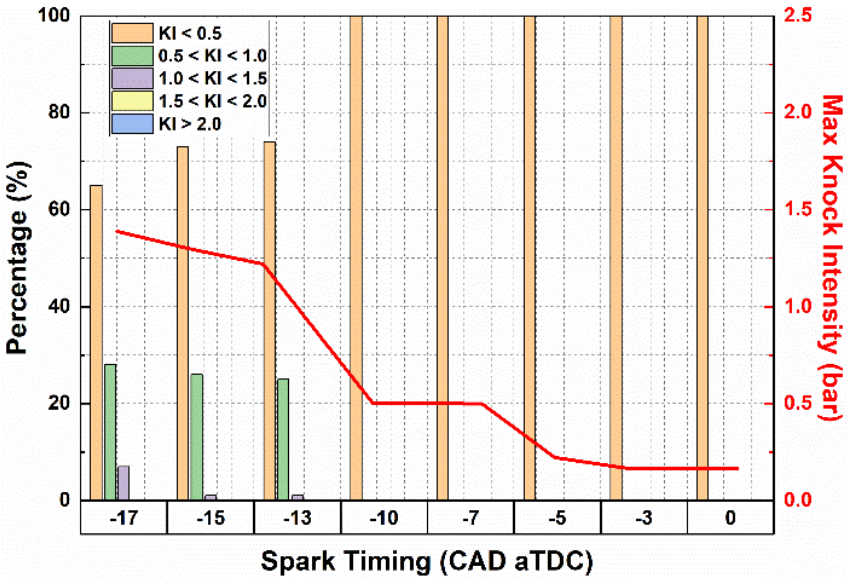

d) Spark plug: $1+2+3+4$

Fig. 11. The percentages of different knock intensity zones and max knock intensities regarding various spark timings and spark strategies

Figure 11 shows the percentages of zones for different knock intensity ranges, with respect to various ST and spark strategies. Overall, the late ignition timing ranging from -10 CAD aTDC to TDC leads to low knock intensity, since the KI zone below 0.5 bar counts for almost $100 \%$ among all the knock intensity zones. Noteworthy, the spark timing range with all the knock intensities below 0.5 bar are different for various spark strategies. For example, the range for igniting plug 1 is from -17 CAD aTDC to TDC, while for other multiple spark ignition strategies, the earlier ST boundary are delayed to -10 CAD aTDC. Consequently, the knock occurrence is more accessible for multiple spark strategies and the knock intensity tends to be higher than single spark ignition.

As is shown in Fig. 11a, with advancing the ST, the percentage of KI $<0.5$ reduces significantly, which is shifted to zones with higher values. Besides, the proportion with KI ranges from 0.5 bar to 1 bar increase significantly at first, then gradually reduce when advancing the spark timings. In comparison, the percentages of zones with KI > 1 bar arise continually, which are attributed to the high in-cylinder pressure and temperature along with early STs. At the same time, the maximum knock intensities of different spark strategies stay at low level at late STs. Along with the advancing of ST, these utmost KI values rise remarkably then stabilize at certain turning points. Additionally, the more spark ignition sites, the later of the turning point, which denotes that spark timing has less impact on the knock intensity with more spark ignition sites.
Compared with individually igniting plug 1 , both of sparking plugs $1+3$ and plugs $1+2+3$ lead to higher peak value of maximal knock intensities under different STs, which illustrate that multiple spark ignitions could exacerbate the knock events. However, the peak value is declined from 5.6 bar to 4.5 bar when switching from triggering plugs $1+3$ to plugs $1+2+3$, and this value can be further reduced to 1.3 bar approximately, which denote that overmuch spark sites could 'kill' the auto-ignition and effectively reduce the knock intensity. In addition, the percentage of higher KI zones with sparking plug 1+3 rise remarkably at early STs, e.g. $-15,-17$ and -20 CAD aTDC. This phenomenon reveals that triggering multiple spark plugs simultaneously induces more intense engine knock, as the in-cylinder pressure and temperature tend to be higher with bringing forward the spark timing.

As can be seen from Fig. 11b and Fig. 11c, in comparison with sparking plugs $1+3$, the high $\mathrm{KI}$ percentages of sparking plugs $1+2+3$ continually rise up when advancing the ST earlier than $-13 \mathrm{CAD}$ aTDC. However, the shares of low knock zones (e.g. KI $<0.5,0.5<$ $\mathrm{KI}<1)$ are relatively high. For example, at the ST of $-13 \mathrm{CAD}$ aTDC, the proportion of KI $<0.5$ with sparking plugs $1+3$ decreases below $80 \%$, while the percentage for sparking plugs $1+2+3$ is still above $95 \%$. What's more, in terms of triggering plugs $1+2+3$ at the same time, both of the portions of $\mathrm{KI}<0.5$ and $0.5<\mathrm{KI}<1$ are higher than those of triggering plugs $1+3$ at the STs of -15 and -17 CAD aTDC. In contrast, the shares of KI > 1 zones are relatively low for sparking plugs $1+2+3$, which demonstrate that spark ignition with more plugs could reduce the knock intensity, since the flame propagation is much faster from different sides in cylinder, so less time is left for auto-ignition.

Based on Fig. 11d, it is noteworthy to mention that the spark strategy with all four plugs activated simultaneously could restrict the knock occurrence, since the KI $<0.5$ zone accounts the major part among all the KI ranges, and which plateaus above $60 \%$ at STs earlier than -15 CAD aTDC. On the contrary, the high KI proportion stays very low even at early spark timings.

\section{Mean KI and standard deviation (SD)}

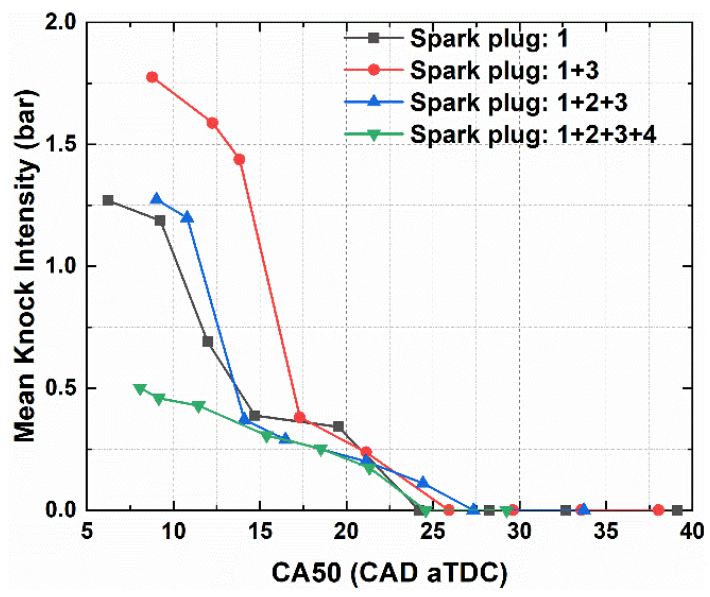

Fig. 12. Mean knock intensities regarding CA50 of different spark strategies 


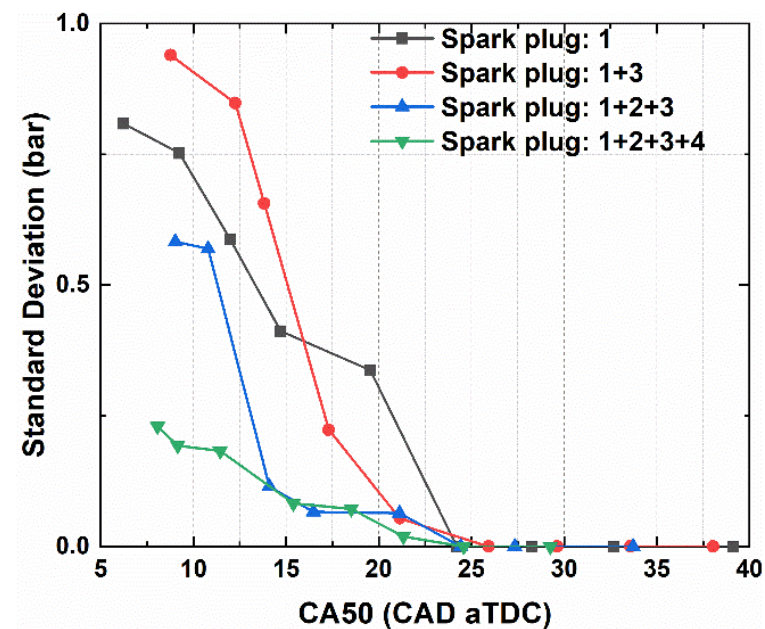

Fig. 13. Standard deviations of knock intensities regarding CA50 of different spark strategies

Figure 12 shows the mean KI variations along with CA50 of different spark strategies. When the CA50 is later than 25 CAD aTDC, the mean knock intensities stay below 0.1 bar, which denotes knock event seldom happen with late combustion phases. As the CA50 is put forward to $17 \mathrm{CAD}$ aTDC, the mean knock intensities are gradually increased to around 0.4 bar. With continuously advancing the CA50, except for sparking the four plugs simultaneously, the mean knock intensities of rest spark strategies grow significantly to high levels. In comparison, when switching plug 1 to igniting plugs $1+3$, the mean KI rises much faster and the peak values are obviously higher. However, when adding one more flame source from sparking plugs $1+3$ to sparking plugs $1+2+3$, the intensity peak value is reduced from 1.8 bar to $1.3 \mathrm{bar}$, which follows the similar way with triggering plug 1 separately. Furthermore, the mean KI of triggering all four spark plugs are kept below 0.5 bar with various of CA50, this denotes that adding proper number of spark plugs promote engine knock, while introducing symmetrically more spark plugs could inhibit the knock occurrence.

Figure 13 displays the standard deviation changes with respect to CA50 for different spark strategies, which follow the similar trends with mean KI. In addition, the high KI is always accompanied by high standard deviation due to the randomness of engine knock. Therefore, highly intensive knock often results to large cyclical variability and dispersed pressure fluctuation. Notably, triggering plugs 1 separately leads to higher deviations than those of sparking plugs $1+2+3$, though their mean KIs are similar. This is because the auto-ignition sites and knock evolution processes of single spark ignition are more random compared with triple spark ignition.

\section{Influential factors on MAPO}

Figure 14 displays the MAPO distributions in relation to different crank angles of $1^{\text {st }}$ oscillation peaks. The MAPO stays at low level when the $1^{\text {st }}$ peak appears after 15 CAD aTDC, and it goes up variously with putting forward the oscillation peak phasing. In particular, among all the spark strategies, sparking four spark plugs simultaneously gives rise to the weakest increase of oscillation amplitude and the peak values stay below 0.5 bar, which is consistent with the mean KI variation trends.

As can be seen in Fig. 14, a linear function $(\mathrm{Y}=-0.25 \mathrm{X}+2.82)$ is fitted to illustrate the overall relation between MAPO and the crank angle of $1^{\text {st }}$ pressure oscillation peak. When the initial peak arises after 15 CAD aTDC, the amplitude of pressure fluctuation is less than 0.4 bar. Before that, the MAPO increases linearly with advancing the $1^{\text {st }}$ oscillation peak phasing. In comparison, the two sites of spark ignition (spark plug: 1+3) leads to utmost amplitude growth, which is followed by three sites (spark plug: $1+2+3$ ) and one site (spark plug: 1) respectively.
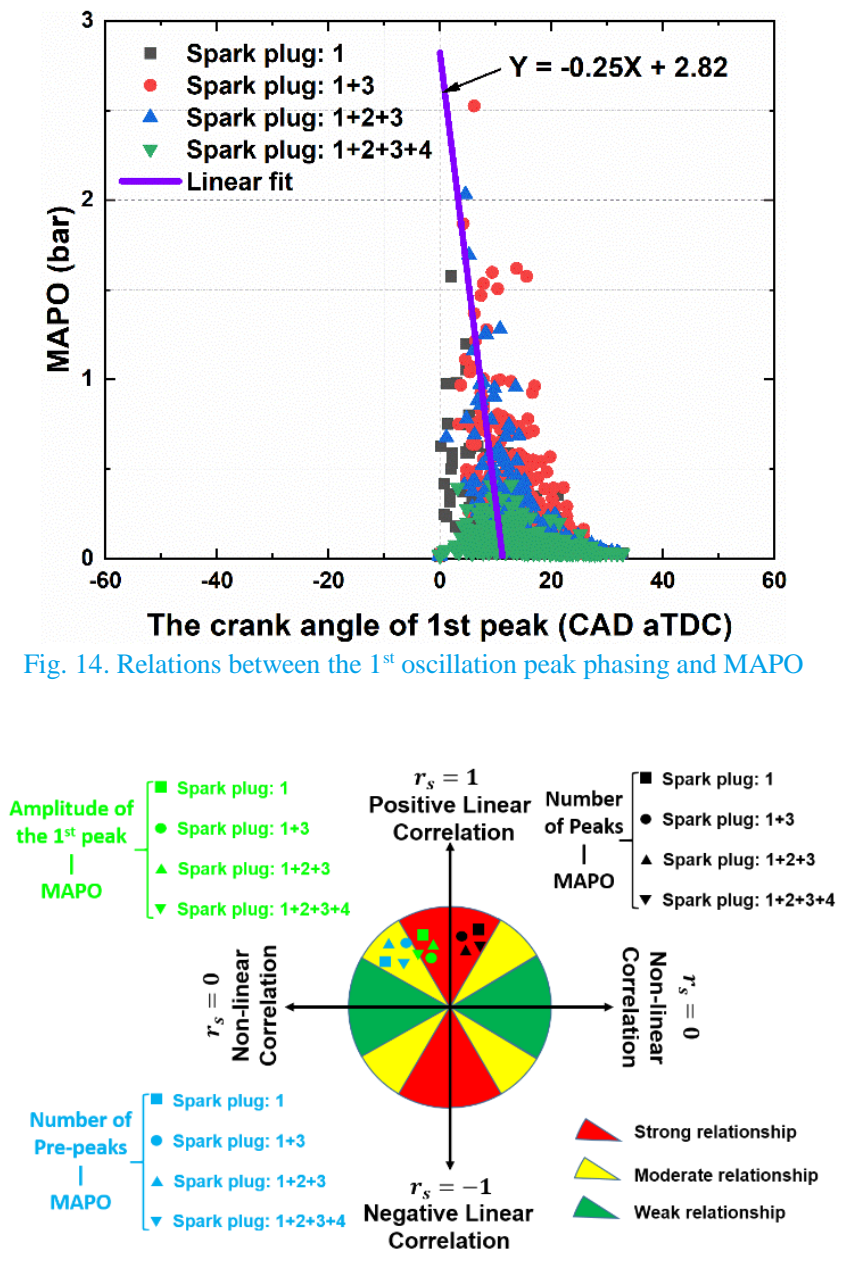

Fig. 15. Spearman correlation coefficients between MAPO and different factors

In order to obtain the correlations between MAPO and additional factors during knock cycles, e.g. the number of pressure vibration peaks, the Spearman correlation coefficients are calculated to illustrate the corresponding influences. In addition, the relationships are divided into three different levels based on the correlation values (Strong: $0.67 \leq r_{s} \leq 1$, Moderate: $0.33 \leq r_{s} \leq 0.67$, Weak: $r_{s} \leq$ 0.33). As is shown in Fig. 15, the number of pressure vibration follows positive linear correlation with MAPO, and these relations are very strong for all the spark strategies, which manifests that more pressure fluctuations are accompanied by higher MAPO. The similar trends exist with the amplitude of the $1^{\text {st }}$ oscillation peak, which indicates that stronger initial peak very likely lead to higher MAPO. Notably, the correlation coefficient for sparking all four plugs is obviously lower than other spark methods, and it locates at the boundary between string and moderate relations. This arises from the fact that both of the MAPO and the initial peak height are insignificant, and which contributes to the low correlation value. 
In terms of the number of pressure vibration peak before the maximum peak (pre-peak), which also follows positive linear relation with the MAPO, and it is same with all the spark strategies.

Moreover, all of these relationships locate into the moderate zone $\left(0.33 \leq r_{s} \leq 0.67\right)$, which manifests that more pre-peaks sometimes contributes to higher MAPO either.

\section{Magnitude changes of pressure oscillation peaks at Fixed CA50}

Figures 16 show the variations of average magnitudes of different vibration peaks, which are valued by different probes from different sides of the chamber. In order to compare the peak amplitudes at a similar level, the CA50 is set at 9 CAD aTDC uniformly for different sparking methods. Besides, these peaks are numbered from -5 to 5 to trace the peak amplitude variations with time. Among them, peak 0 refers to the maximum pressure oscillation peak, while the negative ones represent the oscillation peaks before the maximum one, and the positive ones stand for the oscillation peaks after the maximum peak.

As is shown in Fig. 16a, the MAPO values of different spark strategies follow the same trends with those of mean knock intensities depicted by Fig. 12. However, when comparing with these graphs, the different transducers give different values for every case, which verifies the disparity of pressure distribution and pressure propagation processes in cylinder. Moreover, side 1 and side 3 sensors demonstrate similar peak variations respecting different sparking methods, while another two side sensors exhibit other almost identical trends and amplitudes. Consequently, these facts imply the directional pressure wave transmissions across the combustion chamber, which lead to the particularly similar results of side sensors at opposite positions.

Moreover, although the pre-oscillation (negative index) and postoscillation (positive index) peaks follow the overall upward and downward trends respectively, both of them showcase some zigzags of amplitudes during the vibration processes. Generally, the postoscillation peaks possess more fluctuations in amplitude than the preoscillation ones, which may because the maximum vibration peak could trigger more secondary pressure wave in different directions, which contribute to the rises and falls of main wave magnitude by wave resonance and interference.

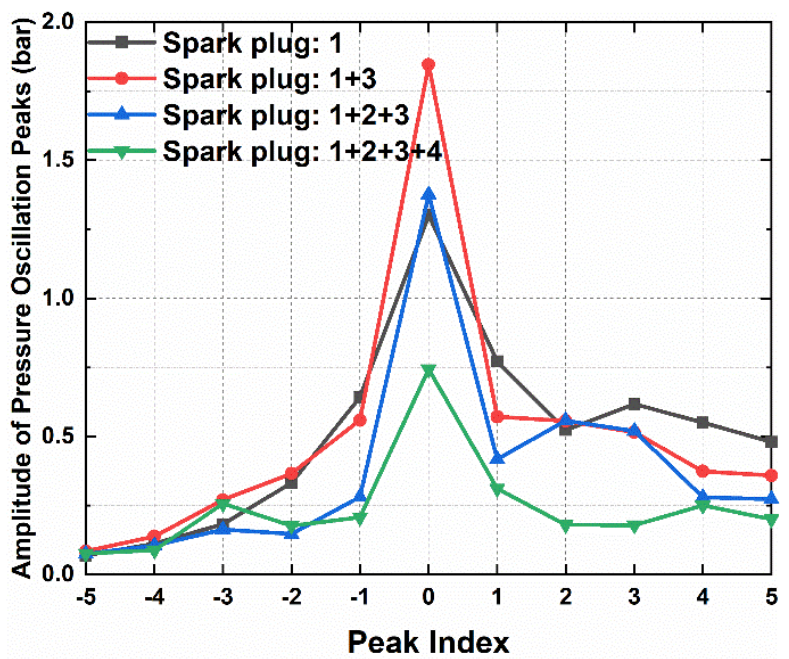

a) top sensor

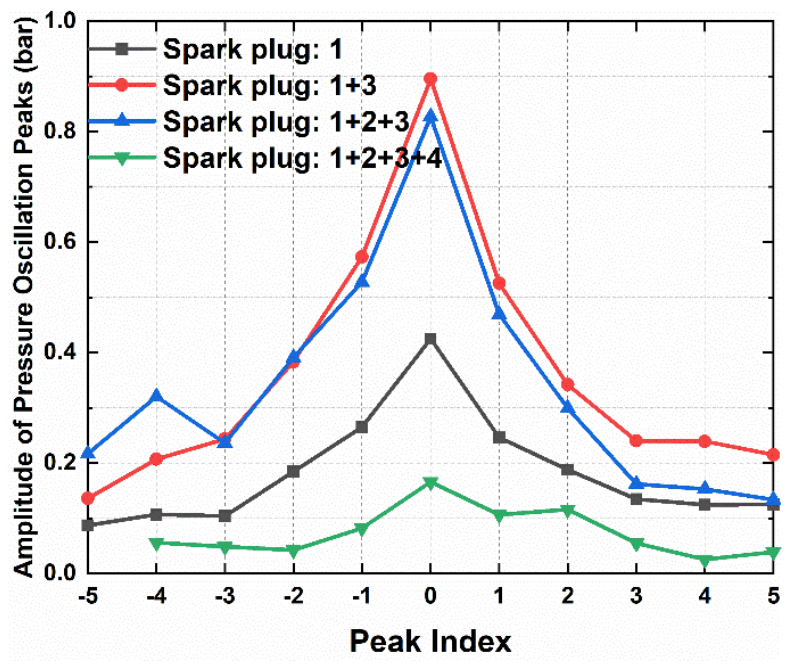

b) side1 sensor

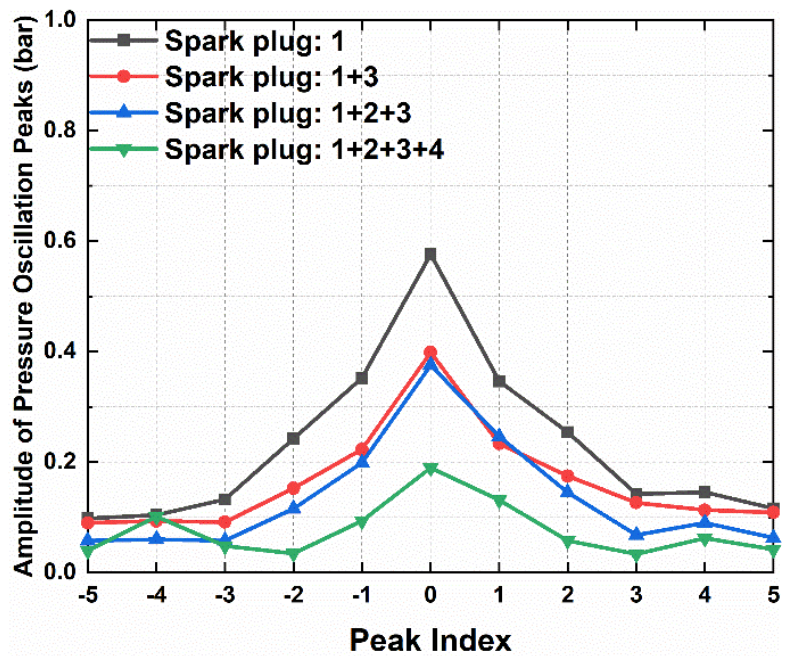

c) side 2 sensor

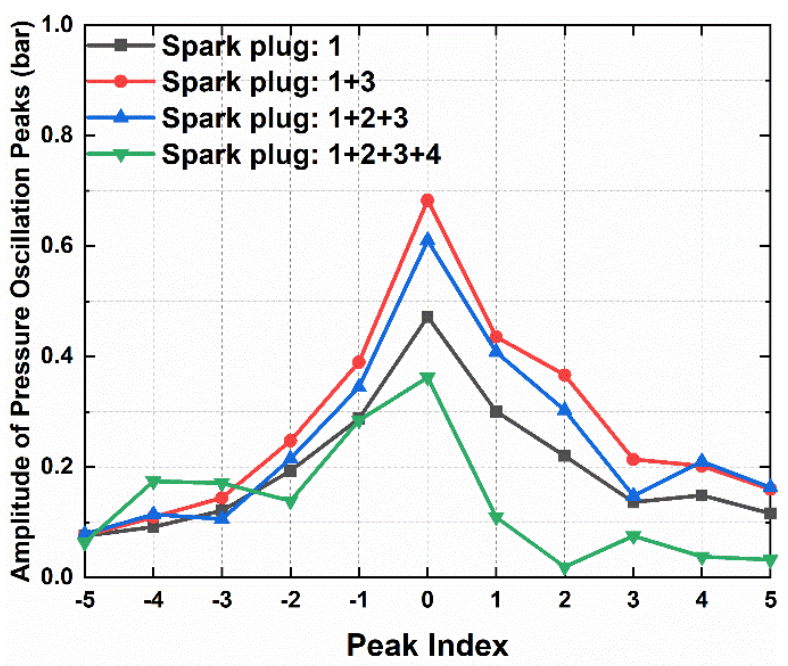

d) side3 sensor 


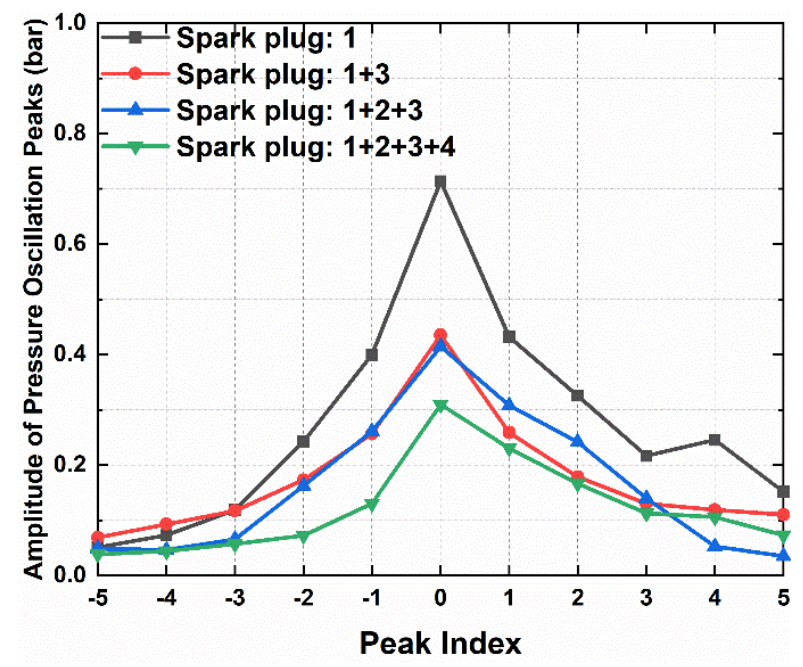

e) side4 sensor

Fig. 16. Magnitude changes of pressure oscillation peaks regarding different spark strategies

\section{Heat release fractions at knock with CA50 at 9 CAD aTDC}

Figures 17 demonstrate the calculated heat release fractions (real time HRR/total HRR) at various pressure oscillation peaks with respect to different sparking strategies. Besides, in order to compared the oscillation peaks and the related heat release fractions at knock concerning various sparking methods and measurement locations, the graphs related to each sensor are put together for convenience. In general, these probes give almost identical heat release fractions at the end of peak 5 (the $5^{\text {th }}$ post-oscillation peak), with all the values ranging from $80 \%$ to $90 \%$, and the quadruple sparking strategy (spark plug: $1+2+3+4$ ) ranks $1^{\text {st }}$ with the single sparking strategy (spark plug: 1) ranks the last.

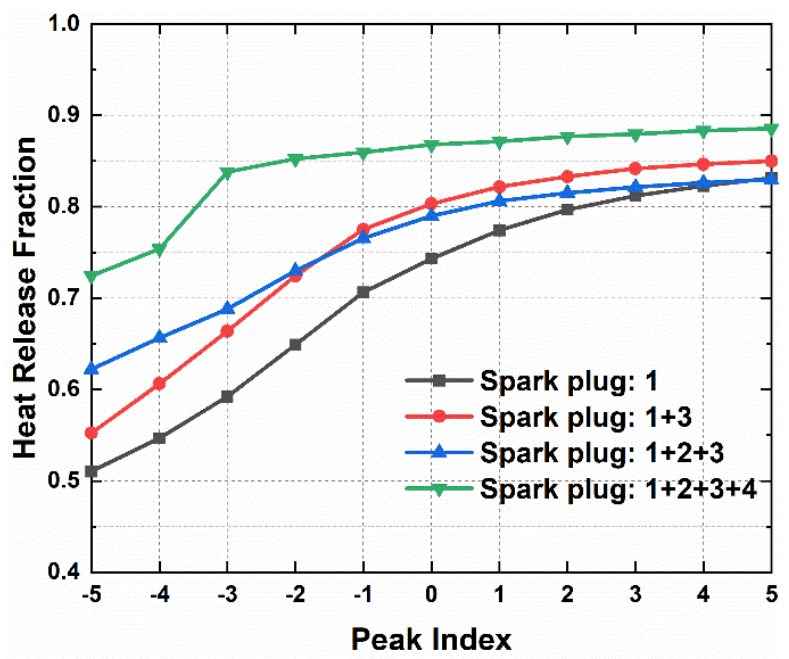

a) top sensor

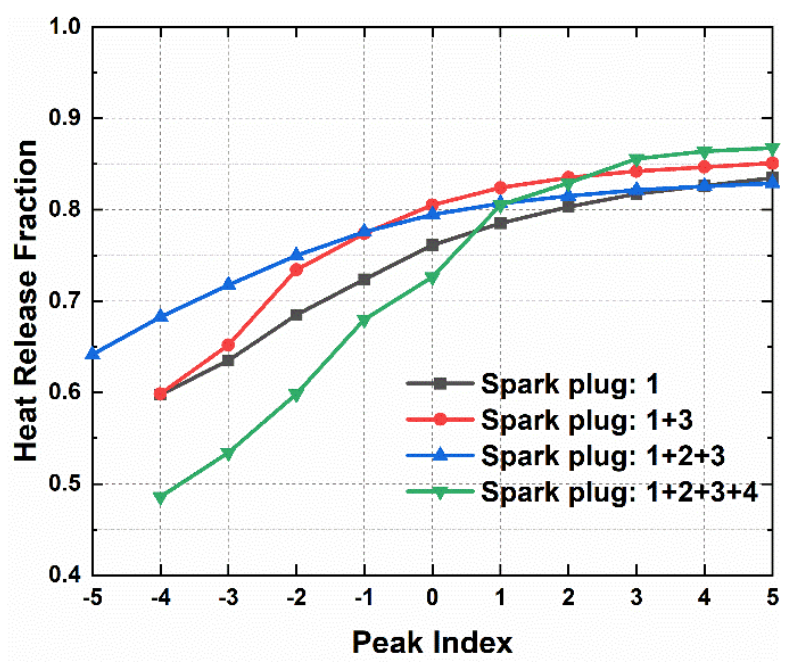

b) side1 sensor

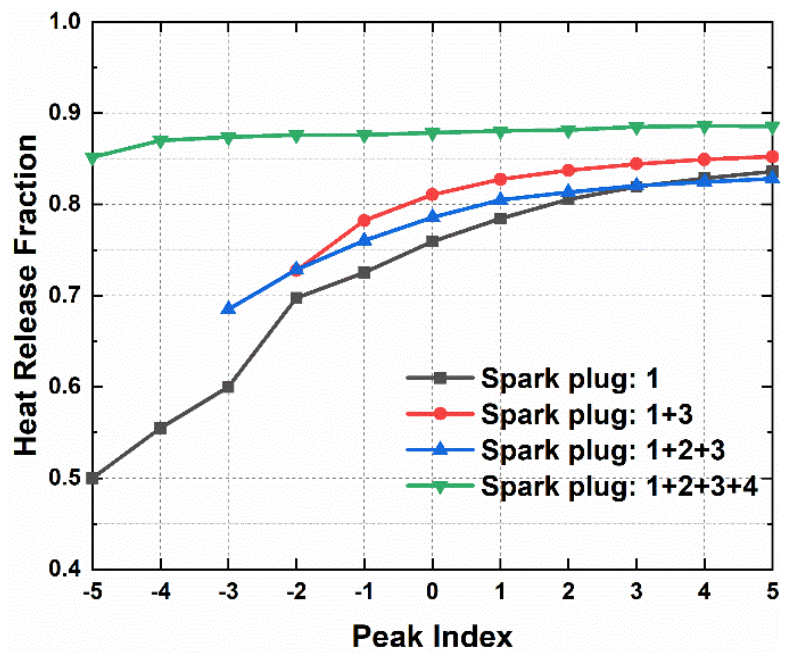

c) side 2 sensor

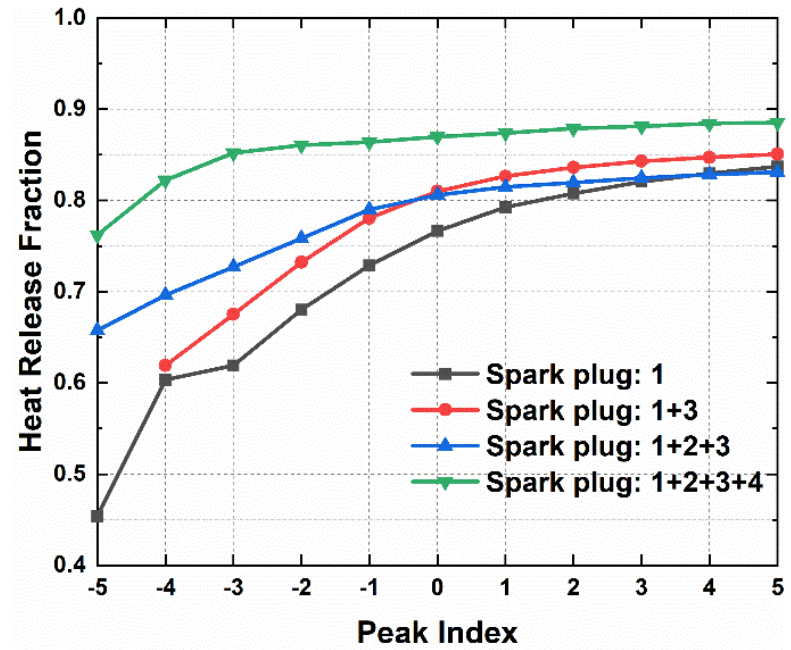

d) side3 sensor 


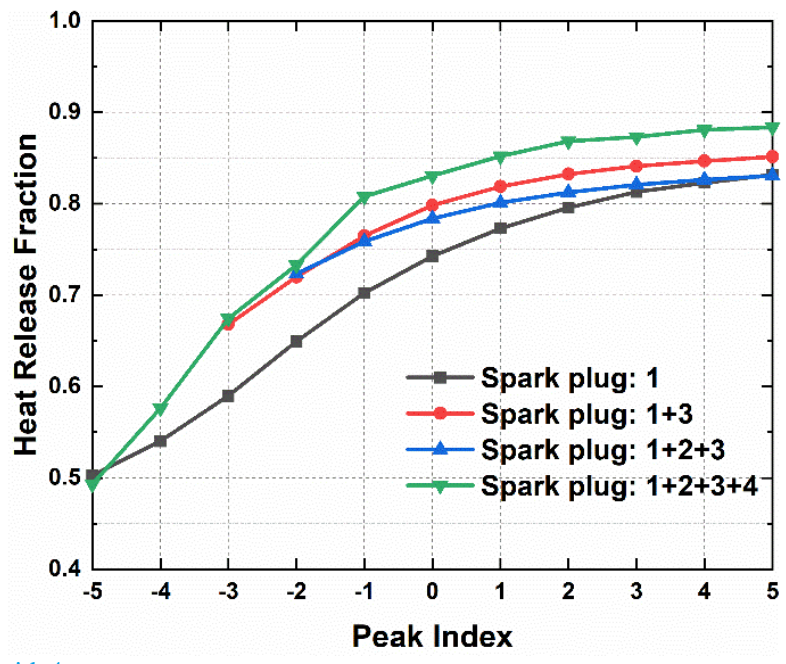

e) side4 sensor

Fig. 17. Heat release fractions at knock regarding different spark strategies

As can be seen from Figs. 17, in terms of activating four plugs simultaneously, all the pressure sensors except the one mounted at side1 location, showcase the highest heat release fractions at early oscillation time among all the sparking methods, as this spark strategy provides the largest flame area during propagation process. However, the side1 sensor exhibits the lowest fractions at preoscillation peaks (peaks -5 - 0) when sparking all four spark plugs. This may be attributed to the weak pressure oscillations for this strategy, and it causes much difference of peak detection time among various pressure sensors.

Figure 17a depicts that the heat release fractions generally follow certain orders with spark plug numbers at pre-oscillation peaks (peaks $-5 \sim 0$ ), i.e. higher activated plug number leads to higher heat release fraction, and this is consistent with the flame areas in combustion chamber. However, at post-oscillation time (peaks $0 \sim$ 5) the heat release fraction of durable spark ignition (spark plug: $1+3$ ) grows fast and can overpass that of triple spark ignition (spark plug: $1+2+3)$. As is shown in Fig. 12, since the durable spark ignition strategy usually possesses stronger knock than that of triple spark ignition strategy, conclusions can be drawn that higher knock intensity leads to higher HRRs during pressure oscillation processes.

Moreover, the results given by sensors 2 and 4 (Figs. 16c, 16e, 17c, 17e) show that the peak oscillation amplitudes and the heat release fractions follow the opposite orders respect different spark strategies. For example, the single spark ignition (spark plug: 1) leads to highest peak amplitudes while the quadruple spark ignition (spark plug: $1+2+3+4)$ gives the lowest peak height. Conversely, the former sparking method results to the minimal heat release fractions while the latter one gives the upmost fractions at knock. Consequently, low degree of pressure oscillation can improve the heat release fraction at knock onset. Moreover, according to the HRRs given by different probes, the measurement location also affect the HRR during pressure oscillations.

\section{Effects of measurement location on MAPO}
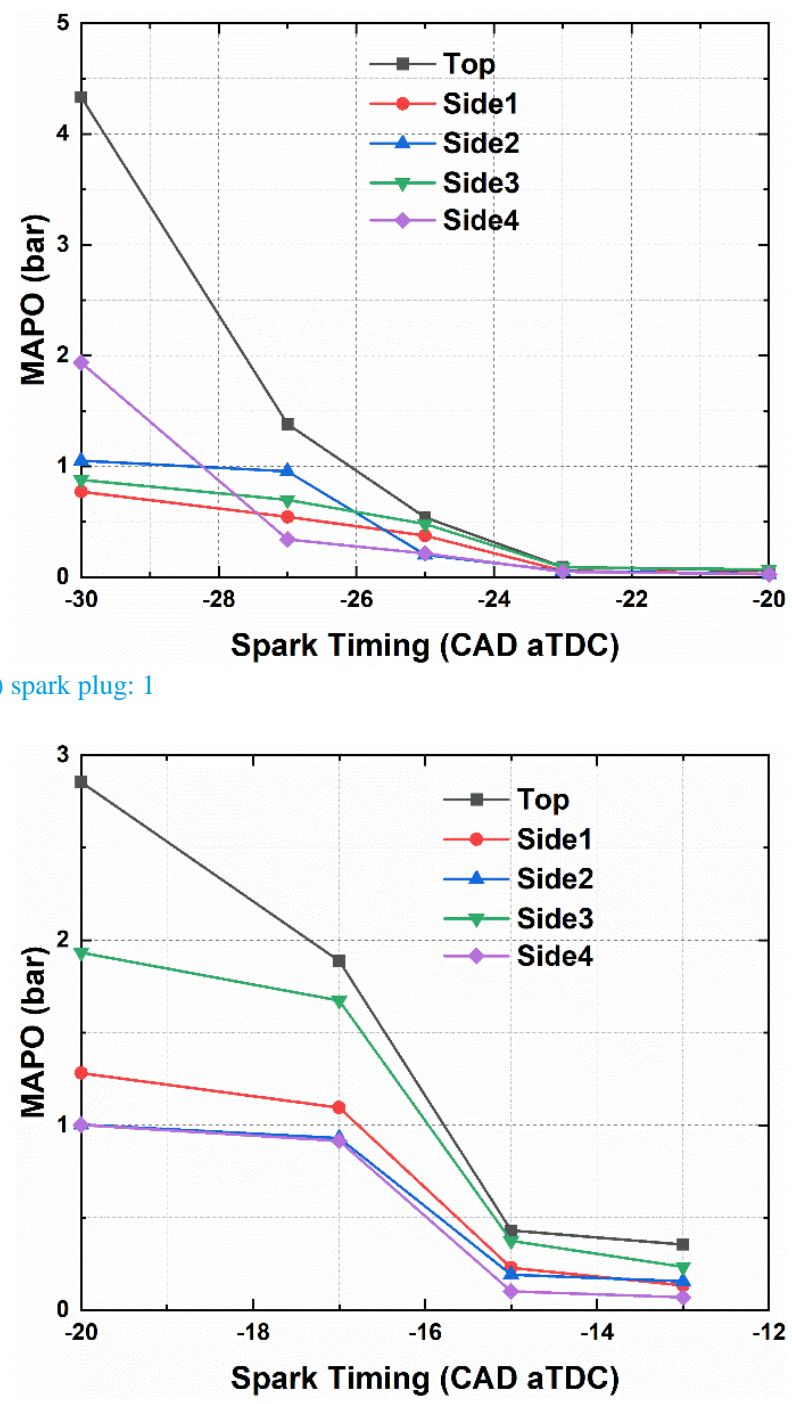

b) spark plug: $1+3$

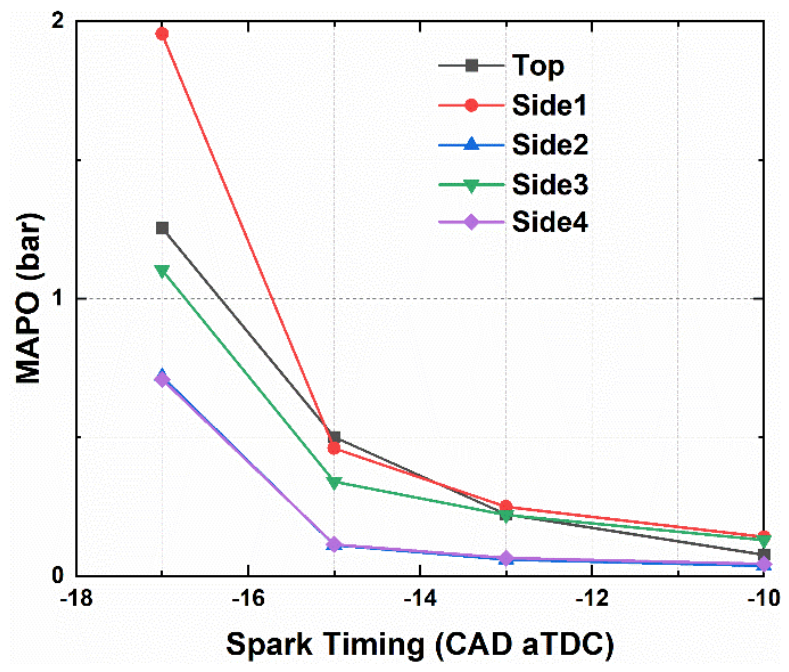

c) spark plug: $1+2+3$ 


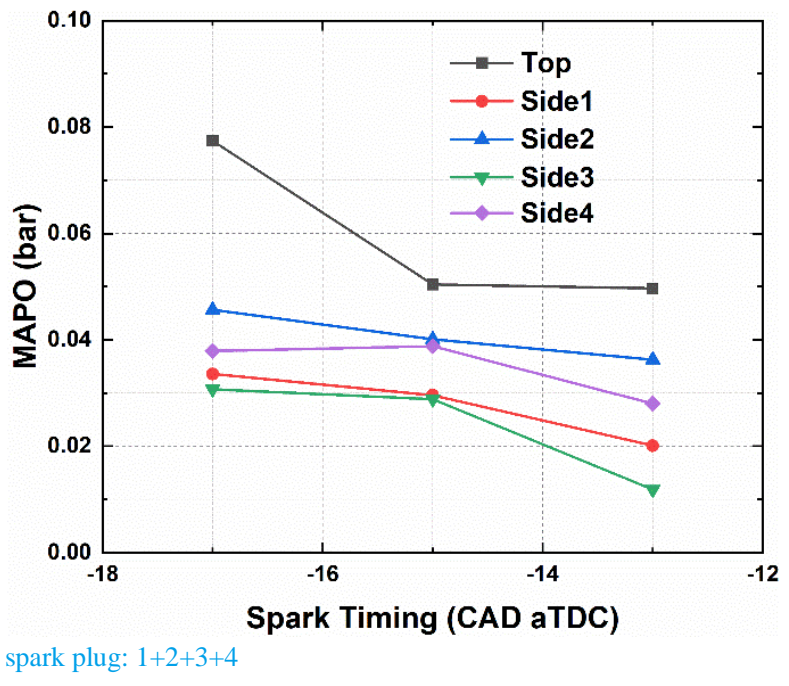

Fig. 18. Maximum oscillation magnitude with different measurement locations

Figure 18a displays maximum oscillation magnitudes for single spark ignition (spark plug 1) measured by pressure transducers amounted at different locations. As the ST goes forward, pressure oscillation caused by engine knock becomes more intense. Besides, the top pressure sensor gives highest fluctuation peak generally, which is similar with the plots shown in Figs. 16. In addition, when the ST is later than -25 CAD aTDC, the 1st and 3rd side sensors give higher oscillation intensities than those by the 2 nd and 4 th side sensors. It denotes that the first two side sensors are alongside the pressure wave propagation, while another two side sensors are in the vertical direction. With advancing the ST, the fluctuation intensity given by the 2 nd and 4th side sensors surpass the values revealed by another two side sensors, this implies that the auto-ignition position and wave transmission direction have been changed.

Figures 18b-18d demonstrate the maximal oscillation magnitudes quantified by various sensors with multiple spark ignition. Comparing with triggering plug 1 individually, triggering plugs $1+3$ and plugs $1+2+3$ could improve pressure fluctuation strength at late STs. On the contrary, activating all four spark plugs could sufficiently suppress the fluctuation during knock cycles.

Notably, based on the oscillation magnitude variations, these four pressure sensors mounted around the liner can be divided into two groups. Besides, the group along the pressure wave spreading path provide higher fluctuation peak values than another group in the perpendicular direction. Furthermore, as is shown in Fig. 18c, the 3rd side sensor gives higher value than the top pressure sensor, which may due to the fact that the pressure wave crest is closer to the side sensor.

\section{Summary/Conclusions}

This study aims at investigating the knock inception mechanism, and the relationships among knock intensity, pressure oscillation and different influence factors during knock cycles. A specialized liner with installing 4 side spark plugs are used to produce various flame propagation processes. Various spark strategies (e.g. spark timing, spark number, spark location) are applied to generate different autoignition sites and knock characteristics. Based on the 4 side pressure sensors mounted on the metal liner and another one on the cylinder head, multiple channels of pressure signal are collected to analyze the knock intensities regarding different spark strategies. The in-cylinder pressure is band-pass filtered to obtain the pressure vibration numbers and peak amplitudes. Furthermore, different influential factors on MAPO and the effects of measurement locations are analyzed. With respect to the proposed research questions, the key conclusions are listed as follows:

1. With adding more ignition source, increasing number of spark plugs lead to higher pressure rise rate and heat release rate, as well as earlier combustion phasing. Besides, multiple spark ignitions allow the spark timing being retarded around $10 \mathrm{CAD}$ to get stable combustion.

2. Compared with the single spark ignition, applying two spark plugs is more accessible to knock and results to higher knock amplitude, since it produces higher in-cylinder pressure and temperature. By comparing the pressure oscillations measured by different sensors, we know that the strongest oscillation peak may happen near the activated spark plug in some cases, instead of the end-gas zone, where the auto-ignition supposed to initiate.

3. When switching from double spark ignition to triple spark ignition, the mean KI would be reduced obviously, to similar level with single spark ignition. In addition, measurement results demonstrate that the highest pressure vibration peak takes place near the spark plugs instead of end-gas region.

4. Additionally, in comparison with other sparking methods, triggering the four side spark plugs simultaneously could effectively suppress the knock strength and the rate of recurrence. It denotes that overmuch symmetrical spark sites could effectively 'kill' the autoignition and reduce the knock intensity, as the flame propagation is much faster from different sides in cylinder, the end-gas area is smaller and less time is left for auto-ignition. Besides, higher knock intensity and less ignition sites result to higher cyclical variability.

5. A liner function of $Y=-0.25 X+2.82$ is fitted to illustrate the relationship between the crank angles of 1 st peaks and MAPO. Moreover, both of the vibration peak number and the amplitude of the 1st peak follow strong positive linear correlations with MAPO, and the number of pre-peaks has moderate positive linear relation with the MAPO.

6. According to the heat release fractions at knock onset, there is always less energy is left for auto-ignition with more spark plugs, because of the higher HRRs. In addition, two side sensors (side2 and side4) reveal that the less energy is left over at knock onset, the lower of the peak amplitude would be. However, this is not applicable to other sensors, and it implies that the peak magnitude at knock onset is not only determined by the number of spark plugs, but also by the measurement location.

7. In terms of the five pressure transducers located at different parts of the cylinder, they do not give the identical results of pressure fluctuation and heat release, which confirm the directionality of pressure wave transmission during knock process. Furthermore, the four side sensors could be divided into two groups, as the sensors located face-to-face always display similar peak amplitude variation trends. This fact manifests that the pressure vibration amplitude along the wave propagation path differs from that in the vertical direction, and this phenomenon will be researched further. 


\section{References}

1. Shu, G., J. Pan, and H. Wei, Analysis of onset and severity of knock in SI engine based on in-cylinder pressure oscillations. Applied Thermal Engineering. 51(1-2): p. 1297-1306.

2. Heywood, J.B., Combustion engine fundamentals. $1^{\mathrm{a}}$ Edição. Estados Unidos, 1988.

3. Wakeel, et al., Exploring the potential of compressed natural gas as a viable fuel option to sustainable transport: A bibliography (2001-2015).

4. Chen, L., et al., A predictive model for knock onset in spark-ignition engines with cooled EGR. Energy Conversion \& Management. 87: p. 946-955.

5. Johansson, B., Internal Combustion Engines. Vol. 1. 2016.

6. Fontanesi, S., et al., Knock tendency prediction in a high performance engine using LES and tabulated chemistry. SAE International Journal of Fuels and Lubricants, 2013. 6(1): p. 98-118.

7. Netzer, C., et al., Three-dimensional computational fluid dynamics engine knock prediction and evaluation based on detailed chemistry and detonation theory. International Journal of Engine Research, 2018. 19(1): p. 33-44.

8. Wang, Z., F. Li, and Y. Wang, A generalized kinetic model with variable octane number for engine knock prediction. Fuel, 2017. 188: p. 489-499.

9. Siokos, K., Z. He, and R. Prucka, Assessment of ModelBased Knock Prediction Methods for Spark-Ignition Engines. 2017, SAE Technical Paper.

10. d'Adamo, A., et al., A RANS knock model to predict the statistical occurrence of engine knock. Applied energy, 2017. 191: p. 251-263.

11. Liu, H., et al., Super-knock suppression for highly turbocharged spark ignition engines using the fuel of propane or methanol. Energy, 2019. 169: p. 1112-1118.

12. Singh, E. and R. Dibble, Effectiveness of fuel enrichment on knock suppression in a gasoline spark-ignited engine. 2018, SAE Technical Paper.

13. Yang, Y., et al., Understanding fuel anti-knock performances in modern SI engines using fundamental HCCI experiments. Combustion and Flame, 2015. 162(10): p. 4008-4015.

14. Zhen, X., et al., The engine knock analysis-An overview. Applied Energy, 2012. 92: p. 628-636.

15. Sileghem, L., T. Wallner, and S. Verhelst, A quasidimensional model for SI engines fueled with gasolinealcohol blends: Knock modeling. Fuel, 2015. 140: p. 217226.

16. Rudloff, J., et al., Analysis of pre-ignition in highly charged SI engines: Emphasis on the auto-ignition mode.

Proceedings of the Combustion Institute, 2013. 34(2): p. 2959-2967.

17. Bares, P., et al., A new knock event definition for knock detection and control optimization. 2018. 131: p. 80-88.

18. Pöschl, M., T.J.C. Sattelmayer, and Flame, Influence of temperature inhomogeneities on knocking combustion. 2008. 153(4): p. 562-573.

19. Kawahara, N., E. Tomita, and Y.J.P.o.t.C.I. Sakata, Autoignited kernels during knocking combustion in a sparkignition engine. 2007. 31(2): p. 2999-3006.

20. Davis, G.W., J. Bouboulis, and E. Heil, The Effect of Multiple Spark Discharge on the Cold-Startability of an E85 Fueled Vehicle. SAE transactions, 1999: p. 955-958.

21. Davis, G.W., J. Bouboulis, and E. Heil, The Effect of a Multiple Spark Discharge Ignition System and Spark Plug
Electrode Configuration on Cold Starting of a Dedicated E85 Fueled Vehicle. 1999, SAE Technical Paper.

22. Poggiani, C., et al., Optical investigations on a multiple spark ignition system for lean engine operation. 2016, SAE Technical Paper.

23. Yu, S., M. Wang, and M. Zheng, Distributed electrical discharge to improve the ignition of premixed quiescent and turbulent mixtures. 2016, SAE Technical Paper.

24. Alger, T., et al., Cooled exhaust-gas recirculation for fuel economy and emissions improvement in gasoline engines. International Journal of Engine Research, 2011. 12(3): p. 252-264.

25. Narasimha Bailkeri, K.P.S., Performance study on twin plug spark ignition engine at different ignition timings. 2013.

26. Yang, Z., et al., A Study of Energy Enhanced Multi-Spark Discharge Ignition in a Constant-Volume Combustion Chamber. 2019, SAE Technical Paper.

27. Cavina, N., et al., Development of a multi-spark ignition system for reducing fuel consumption and exhaust emissions of a high performance gdi engine. 2011, SAE Technical Paper.

28. Tanoue, K., et al., Extension of lean and diluted combustion stability limits by using repetitive pulse discharges. 2010, SAE Technical Paper.

29. Piock, W.F., et al., Ignition systems for spray-guided stratified combustion. SAE International Journal of Engines, 2010. 3(1): p. 389-401.

30. Kartha, B.N., S. Vijaykumar, and P. Reddemreddy, Thermodynamic Split of Losses Analysis of a Single Cylinder Gasoline Engine with Multiple Spark PlugIgnition Coil Configurations. 2016, SAE Technical Paper.

31. Pasternak, M., et al., OD/3D simulations of combustion in gasoline engines operated with multiple spark plug technology. 2015, SAE Technical Paper.

32. Galloni, E., Dynamic knock detection and quantification in a spark ignition engine by means of a pressure based method. Energy conversion and management, 2012. 64: p. 256-262.

33. Merola, S.S. and B.M. Vaglieco, Knock investigation by flame and radical species detection in spark ignition engine for different fuels. Energy conversion and Management, 2007. 48(11): p. 2897-2910.

34. Pöschl, M. and T. Sattelmayer, Influence of temperature inhomogeneities on knocking combustion. Combustion and Flame, 2008. 153(4): p. 562-573.

35. Wei, H., et al., A numerical study on pressure waveinduced end gas auto-ignition near top dead center of a downsized spark ignition engine. International journal of hydrogen energy, 2014. 39(36): p. 21265-21274.

36. Terashima, H., A. Matsugi, and M. Koshi, End-gas autoignition behaviors under pressure wave disturbance. Combustion and Flame, 2019. 203: p. 204-216.

37. Wei, H., et al., One-dimensional numerical study on pressure wave-flame interaction and flame acceleration under engine-relevant conditions. International Journal of Hydrogen Energy, 2015. 40(14): p. 4874-4883.

38. Wang, Z., H. Liu, and R.D. Reitz, Knocking combustion in spark-ignition engines. Progress in Energy and Combustion Science, 2017. 61: p. 78-112.

39. Chen, Y. and R. Raine, A study on the influence of burning rate on engine knock from empirical data and simulation. Combustion and Flame, 2015. 162(5): p. 2108-2118.

40. Li, T., T. Yin, and B. Wang, A phenomenological model of knock intensity in spark-ignition engines. Energy Conversion and Management, 2017. 148: p. 1233-1247. 
41. Kalghatgi, G., et al., Knock prediction using a simple model for ignition delay. 2016, SAE Technical Paper.

42. Kalghatgi, G., I. Algunaibet, and K. Morganti, On knock intensity and superknock in SI engines. SAE International Journal of Engines, 2017. 10(3): p. 1051-1063.

43. Amann, M. and T. Alger, Lubricant reactivity effects on gasoline spark ignition engine knock. SAE International Journal of Fuels and Lubricants, 2012. 5(2): p. 760-771.

44. Worret, R., et al., Application of different cylinder pressure based knock detection methods in spark ignition engines. SAE Transactions, 2002: p. 2244-2257.

45. Mittal, V., B.M. Revier, and J.B. Heywood, Phenomena that determine knock onset in spark-ignition engines. SAE Transactions, 2007: p. 14-22.

46. Piantadosi, J., Matching the grade correlation coefficient using a copula with maximum disorder. Journal of Industrial \& Management Optimization. 3(2): p. 305-312.

\section{Contact Information}

Hao Shi

PhD student

Clean Combustion Research Center

King Abdullah University of Science and Technology, KAUST

Building 5, Level 4, Thuwal 23955-6900, Kingdom of Saudi Arabia

Mobile: +966 545395987

E-mail: hao.shi@kaust.edu.sa

\section{Acknowledgments}

The authors would like to acknowledge the King Abdullah University of Science and Technology (KAUST) for the research funding, and thanks to Adrian I. Ichim and Riyad Jambi in KAUST CCRC for the support during the experiment.

\section{Definitions/Abbreviations}

\section{CD}

combustion duration compression ignition

DDT

deflagration to detonation Transition

ECU

electronic control unit

HRR

heat release rate

KI

knock intensity

MAPO

maximum amplitude of pressure oscillation

MON

motor octane number

PвpF

band-pass filtered pressure

PFI

port fuel injection

Pmax

maximum in-cylinder pressure

RON

research octane number

SD

standard deviation

SG

specific gravity

SI

spark ignition

ST

spark timing

TDC

top dead center

UHC

unburned hydrocarbon 